\title{
İKİ AMAÇLI FARKLI MAKİNE SEÇENEKLİ KAPALI DÖNGÜ TEDARİK ZİNCİRİ OPTIMIZASYONU: BULANIK ÇÖZÜM TEKNIĞİ UYGULAMASI
}

\author{
${ }^{1}$ Batuhan Eren ENGİN, ${ }^{2 T}$ Turan PAKSOY \\ 1,2 Konya Teknik Üniversitesi, Mühendislik ve Doğa Bilimleri Fakültesi, Endüstri Mühendisliği Bölümü, \\ Konya, Türkiye \\ 1erengn@gmail.com, 2tpaksoy@yahoo.com
}

(Geliş/Received: 12.11.2018; Kabul/Accepted in Revised Form: 18.12.2018)

\begin{abstract}
ÖZ: Tedarik zinciri yönetimi, küreselleşme çağının başlangıcından beri akademisyenlerin ve uygulayıcıların artan ilgisini çekmeye devam etmiştir. Son yıllarda, tedarik zinciri yönetiminin odak noktası, enerji tüketimi, karbon emisyonları gibi ekonomik, sosyal ve çevresel yönlerin ortaklaşa ele

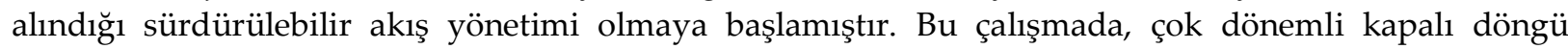
tedarik zinciri ağ tasarım probleminin optimizasyonu için iki amaçlı karmaşık tamsayılı doğrusal programlama modelinin formüle edilmesi ve çözülmesi gerçekleştirilmiştir. Model, farklı makine tiplerinde faaliyet gösteren tesislerin toplam operasyon maliyeti ve toplam karbon emisyonları olmak üzere iki ayrı amacın minimizasyonunu hedeflerken, üretim ve dağıtım stratejilerini belirlemekte ve yeni veya eski tip makinelerin kullanımına da karar vermektedir. Daha eski ve güncel olmayan makinelerin ilk satın alma maliyeti, yeni ve güncellenmiş makinelere göre daha düşük olmasına rağmen, eski makineler, saat başına daha yüksek maliyetle çalışırken yeni makinelere göre saat başına daha fazla karbon salmaktadır. Ayrıca, bir saat içinde üretilen ürünlerin sayısı, yani üretkenlik, yeni makinelerde daha üstündür. Bu iki amaçlı kapalı döngü tedarik zinciri modelinin çözümü için bulanık ağırlıklandırma yaklaşımı kullanılmıştır. Sonuçlar, üretimde yeni nesil teknolojilere yatırım yapılmasının hem ekonomik hem de çevresel amaçlara ulaşmak için önemli olduğunu göstermektedir.
\end{abstract}

Anahtar Kelimeler: Çok Amaçlı Optimizasyon, Kapalı Döngü Tedarik Zincirleri, Karbon Emisyonları, Yeşil Tedarik Zinciri.

\section{A Bi-objective Closed Loop Supply Chain with Different Machinery Options: Application of Fuzzy Weighted Additive Approach}

\begin{abstract}
Supply chain management is an emerging area that drawing increasing attention of academics and practitioners for decades. In recent years, SCM's focal point has begun to emerge as a sustainable flow management, in which economic, social and environmental aspects such as energy consumption, carbon emissions are jointly addressed. This study focused on formulating and solving a bi-objective multi-period closed loop supply chain network design problem. The model determines the production and distribution strategies, while minimizing two objectives simultaneously; the total supply chain cost and the carbon emissions generated by plants operating through different machinery types. While the initial purchase cost of older and more outdated machinery is lower than newer ones, older machinery emits greater amount of carbon per hour as opposed to newer machinery while operating at even greater cost per hour. Besides, the number of products produced in an hour is also higher in newer machinery. We adopted a fuzzy weighted additive approach to solve the bi-objective optimization model. The results confirm that investing in newer technologies in manufacturing comes with great result for both economic and environmental causes, reducing the unit cost and carbon emission per product throughout the manufacturing periods.
\end{abstract}


Keywords: Carbon Emissions, Closed Loop Supply Chains, Green Supply Chain, Multi-Objective Optimization.

\section{GİRIŞ (INTRODUCTION)}

Rekabetçi piyasada şirketler arasında maliyet, fiyat, kalite ve verimlilik açısından zorlu bir rekabet vardır. Böyle bir rekabette avantaj elde etmenin bir yolu da, sunulan ürünlerin kalitesine zarar vermeden imalat ve tedarik zincirinden kaynaklanan çeşitli maliyetleri azaltmaktır (de Groot ve diğ., 2001; Iida, 2012). Bu bağlamda, başta yüksek satın alma maliyeti olmasına rağmen, yüksek verimli, düşük enerji harcayan yeni nesil teknolojilere yatırım yapmak şirketler açısından, hem de çevresel etkileri için önemlidir (Fahimnia ve diğ., 2015; Jaffe ve diğ., 2005). Elbette yeni teknolojiye yatırım yapma kararı da şirketin talep tahminlerine, planlama ufkuna, pazarlama gücüne de bağlı olacaktır. Çevresel performansla ilgilenen şirketler, kısa vadede çevre yönetimi maliyetlerine katlanacak olmasına rağmen uzun dönemde daha fazla kar üretecek ve bu da onların küresel piyasada uzun vadede hayatta kalmasına yardımcı olacaktır (Teng ve diğg., 2014).

Şirketler, bir yandan rekabette bir adım önde olmak için maliyetleri düşürmeye çalışırken, bir yandan da üretimden ve dağıtımdan kaynaklanan çevresel ayak izini bu amaca yönelik çıkarılmış uluslararası mevzuat ve yönetmelikler sebebiyle azaltmak durumundadırlar (Jaffe ve diğ., 2005). Bu nedenle şirketler, genellikle çelişen operasyonel maliyet ve çevresel ayak izi (karbon salınım miktarı, harcanan enerji miktarı, toplam atık miktarı vb.) arasındaki dengeyi bulmayı amaçlamaktadırlar.

Ancak, çevresel etki faktörü yüksek üreticilerin yeni teknolojilere yatırım yapmayı tercih etmesi veya yeni teknolojilerin geliştirilmesi/yayılması, karbon vergisi/ticareti gibi çevresel politikalara bağlıdır. Kanun geliştiriciler, hükümetler karbon emisyonlarını azaltacak yeni teknolojilerin geliştirilmesi ve kullanılması için kaynak kullanımına yönelik teşvik vermeye, emisyonu direkt olarak azaltacak ancak ekstra ekonomik yüklenmelere sebebiyet verecek yöntemlere nazaran daha isteklidirler, bunun da sebebi ise çoğu ülkede politik çoğunluğun yeni teknolojilere yatırım yapılmasını daha çok desteklemesidir. Ayrıca hükümetler bir takım teşviklerle, üreticilere kaynak sağlayan tedarikçilerin emisyon azaltan teknolojilere ilişkin araştırma yapmalarının önünü açmak isteyebilirler. Örneğin Malezya hükümeti, üretim firmalarının yeşil teknolojiye yeterli yatırım yapmasını ve yeni alternatif enerji kaynakları üretmesini sağlamak, yeni yeşil makine ve teknolojinin satın alınmasını finanse etmek için devlet destekli kredide indirimle beraber ile yeşil teknoloji finansman planını uygulamaya koymuştur (Fernando ve Wah, 2017). Ancak, hükümetler tarafından takip edilen politikaların gerçekten faydalı olup olmadığının değerlendirilmesi, böylesi araştırmaların çıtılarının uzun sürelerde ortaya çıkmalarından dolayı zorlayıcıdır (Jaffe ve diğ., 2005). Bu bağlamda ortaya çıkan karbon emisyonu ve maliyet ödünleşmesi durumunu inceleyen araştırmalar önem kazanmıştır.

Çok amaçlı optimizasyon ise literatürde giderek daha fazla görülmeye başlamıştır. Çok amaçlı problemlerin literatürde farklı farklı çözüm teknikleri vardır. Örneğin, amaç fonksiyonları aynı cinsten ifade edilerek, mesela para cinsinden, çoklu amaç tek bir amaca indirgenebilir (Fahimnia ve diğ., 2015). Yazarlar, çalışmalarında karbon emisyonları, enerji tüketimi ve atık üretimi de dahil olmak üzere, maliyet ve çevresel bozulma arasındaki ilişkiyi ele alan bir tedarik zinciri modeli için karma-tamsayılı doğrusal olmayan matematiksel model önermişlerdir ve önerilen matematiksel modelin tüm amaçları, eşdeğer dolar cinsinden ifade edilerek, çok amaçlı model tek bir ağırlıklı toplam amaçlı optimizasyon problemine çevrilerek çözümü gerçekleştirilmiştir. Bazı amaç fonksiyonlarının modele kısıt olarak eklenmesi temeline dayanan $\epsilon$-kısitlama yöntemini bunlardan birisidir (Banasik ve diğg., 2017; Soleimani ve diğ., 2017; Talaei ve diğ., 2016). Pareto cephesini bularak, domine edilmemiş çözüm kümesini bulan çeşitli evrimsel algoritmalar ile de çok amaçlı problemlere çözüm üretilebilmektedir (Altiparmak ve diğ., 2006; Chan ve diğ., 2016; Sadeghi Rad ve Nahavandi, 2018; Wang ve diğ., 2011). Bu çalışmada da kullanılan, Tiwari ve diğ. (1987) tarafından geliştirilen bulanık ağırlıklı çözüm yöntemi de literatürde kullanılan yöntemlerden birisidir (Amid ve diğ., 2009; Arikan, 2013; Kavitha, 2013; Mehlawat ve Kumar,

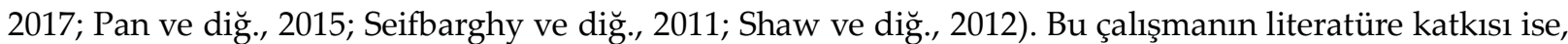
bu metodun geliştirilen çok amaçlı, farklı makine merkez seçeneklerinin olduğu bir modelde, yeni makine yatırımları planlayan yöneticilere yol göstermek için uygulanmış olmasıdır. 


\section{İKI AMAÇLI FARKLI MAKINNE SEÇENEKLİ KAPALI DÖNGÜ TEDARIKK ZINCİRI (BI-OBJECTIVE CLOSED LOOP SUPPLY CHAIN WITH DIFFERENT MACHINERY OPTION)}

Bu çalışmada, fabrikalar, müşteriler, toplama merkezleri içeren 3-aşamalı yeşil bir tedarik zinciri tasarlanmıştır ve 2 düğüm arasında her periyottaki optimal taşıma miktarlarını bulmayı amaçlayan bir matematiksel model oluşturulmuştur. Fabrikalar, farklı parametrelere sahip yeni ve eski tip olmak üzere 2 farklı makine merkezlerinden birini seçip, üretimi gerçekleştirebilir. Daha eski ve güncel olmayan makinelerin ilk satın alma maliyeti, yeni ve güncellenmiş makinelere göre daha düşük olmasına rağmen, eski makineler, saat başına daha yüksek maliyetle çalışırken yeni makinelere göre saat başına daha fazla karbon salmaktadır (Çizelge 1). Ayrıca, bir saat içinde üretilen ürünlerin sayısı, yani üretkenlik, yeni makinelerde daha üstündür. Model, hangi fabrikaların, depoların ve toplama merkezlerinin açılacağını, hangi fabrikalarda hangi tip makinelerin kullanılacağına da karar vermektedir. Modelde, tedarik zincirinin toplam maliyeti ve toplam karbon emisyonları olmak üzere iki ayrı amacın minimizasyonu hedeflenmiştir.

Çizelge 1. Yeni ve eski makine merkezlerinin parametre karşılaştırması Table 1. Parameter comparison of older and newer machine environment

\begin{tabular}{ccccc}
\hline & $\begin{array}{c}\text { Başlangıç satın } \\
\text { alma maliyeti }\end{array}$ & $\begin{array}{c}\text { Saatlik üretim } \\
\text { maliyeti }\end{array}$ & $\begin{array}{c}\text { Saatlik emisyon } \\
\text { miktarı }\end{array}$ & $\begin{array}{c}\text { Saatte üretilen } \\
\text { ürün miktarı }\end{array}$ \\
\hline $\begin{array}{c}\text { Eski makine } \\
\text { merkezi } \\
\begin{array}{c}\text { Yeni makine } \\
\text { merkezi }\end{array}\end{array}$ & Düşük & Yüksek & Yüksek & Düşük \\
\hline
\end{tabular}

Tedarik zincirinin genel şeması ise Şekil 1'de gösterilmiştir.

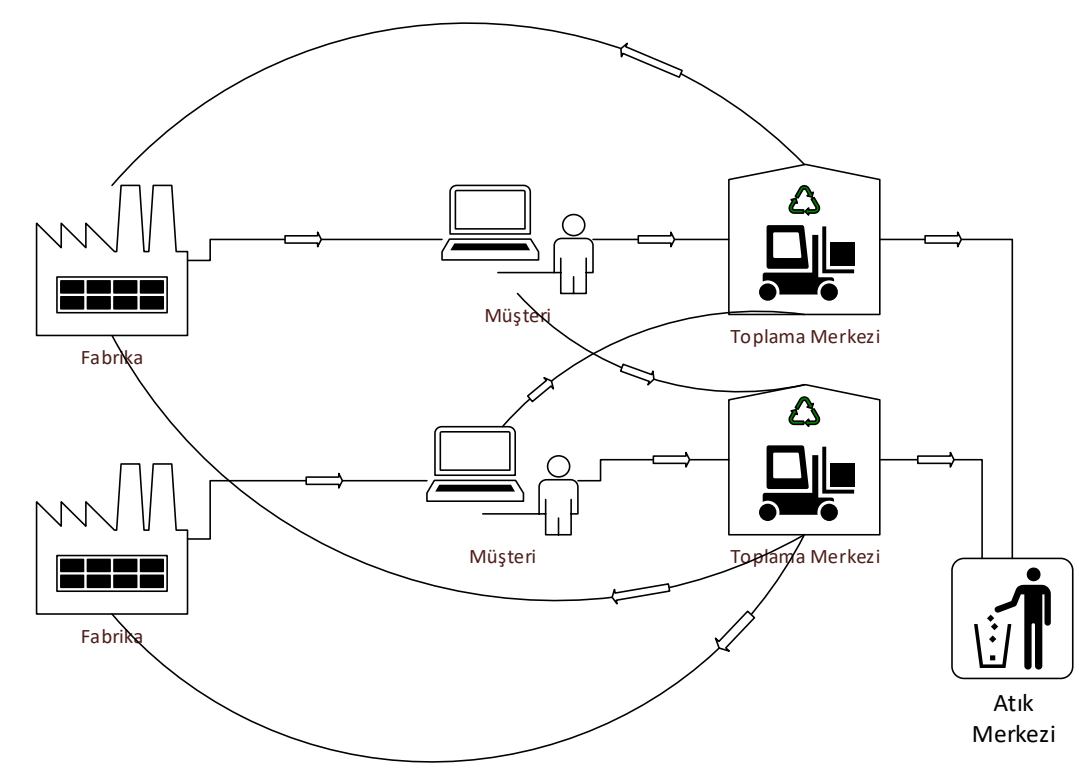

Şekil 1.Tedarik zinciri şeması

Figure 1. Supply chain scheme

Önerilen modelin geliştirilmesinde aşağıdaki varsayımlar kullanılmıştır:

1. Müşterilerin talepleri, planlama öncesinde bilinmektedir. 
2. Çoklu-dönem olarak tasarlanan model, birden fazla fabrika, müşteri ve toplama merkezlerinden oluşmaktadır.

3. Tesislerin, müşterilerin ve toplama merkezlerinin yerleri sabittir.

4. Üreticilerin kurabileceği makine merkezlerinin üretim kapasiteleri bilinmektedir ve sınırlıdır.

5. Her dönem için müşterilerin talepleri karşılanmalıdır.

Bu modelde kullanılan kümeler ve indeksler aşağıdaki gibidir:

I $\quad$ Fabrika kümesi, $i$ ile endeksli

G Makine merkezi kümesi, $g$ ile endeksli

J Müşteri kümesi, $j$ ile endeksli

$\mathrm{T} \quad$ Zaman periyodu kümesi, $t$ ile endeksli

M Toplama merkezi kümesi, $m$ ile endeksli

\section{Değişkenler}

$X_{i g t} \quad$ :i fabrikasında yeni makine merkezi kullanılarak $\mathrm{t}$ döneminde üretilen ürün miktarı

$Y_{i j t} \quad$ :i fabrikasından müşteri j’ye $\mathrm{t}$ döneminde gönderilen ürün miktarı

$Z_{j m t} \quad$ :Müş̧eri j den toplama merkezi m tarafından t döneminde geri kazanılan ürün miktarı

$K_{m i t} \quad$ :Toplama merkezi m'den fabrika i'te t döneminde gönderilen ürün miktarı

$O_{i g} \quad$ :i fabrikasında g makine merkezi kullanılırsa 1, diğer durumda 0

( $\mathrm{g}=1$ iken eski, 2 iken yeni makine merkezi)

\section{Parametreler}

unitp $_{g} \quad$ :makine merkezi g'nin saatlik çalışma maliyeti

dem $_{j t} \quad$ :müşteri j'nin $\mathrm{t}$ dönemindeki talebi

$d i s i j_{i j} \quad$ :fabrika i ile müşteri j arasındaki mesafe

disjm $_{j m} \quad$ :müşteri j ile toplama merkezi $\mathrm{m}$ arasındaki mesafe

dismi $_{m i} \quad$ :toplama merkezi $\mathrm{m}$ ile fabrika i arasındaki mesafe

c :birim ürün taşıma maliyeti

$r c \quad$ :bir ürünün geri kazanım maliyeti

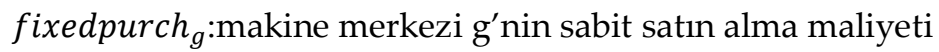

carbon $_{g} \quad$ :makine merkezi g'nin saatte ürettiği karbon emisyon miktarı

$p^{\prime} \quad$ :makine merkezi g'nin saatte ürettiği ürün miktarı

$n_{g} \quad$ :bir periyotta makine merkezi g'nin üretim kapasitesi

$\alpha \quad$ :geri kazanım oranı 


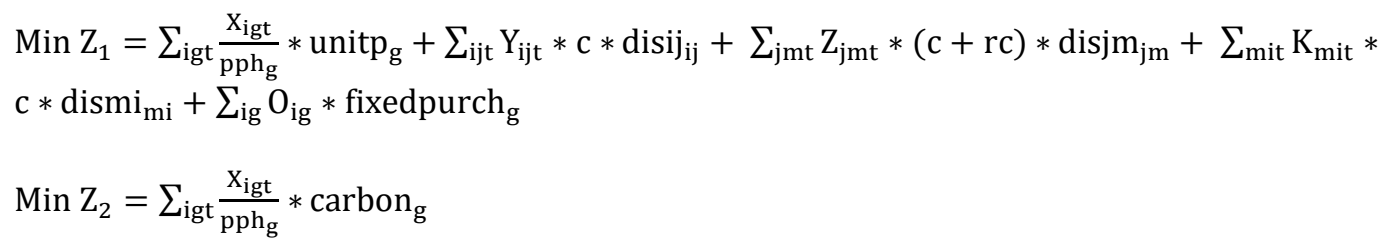

Kisitlar:

$$
\begin{aligned}
& X_{i g t} \leq 24 * p p h_{g} * O_{i g}, \forall \mathrm{i}, \mathrm{g}, \mathrm{t} \\
& \sum_{g} O_{i g} \leq 1, \forall \mathrm{i} \\
& \sum_{g} X_{i g t}+\sum_{m} K_{m i t}=\sum_{j} Y_{i j t}, \forall \mathrm{i}, \mathrm{t} \\
& \sum_{i} Y_{i j t} \geq d e m_{j t}, \forall \mathrm{j}, \mathrm{t} \\
& \sum_{i} Y_{i j t} * \alpha=\sum_{m} Z_{j m(t+1)}, \quad \forall \mathrm{t}, \mathrm{j}\{t \neq T\} \\
& \sum_{j} Z_{j m t}=\sum_{i} K_{m i t}, \forall \mathrm{m}, \mathrm{t} \\
& \sum_{m} K_{m i t} \leq \sum_{g} n_{g} * O_{i g}, \quad \forall \mathrm{i}, \mathrm{t} \\
& X_{i g t}, Y_{i j t}, Z_{j m t}, K_{m i t} \geq 0, \quad \forall i, w, k, j, t \\
& O_{i g} \in\{0,1\}, \quad \forall i, w, k, j, t
\end{aligned}
$$

Denklem (1), toplam üretim, dağıtım, geri kazanım ile ilgili tüm maliyetleri içeren amaç fonksiyonudur. Denklem (2) ise toplam üretimden kaynaklanan ve makinelerin farklı karbon emisyonlarına dayanan amaç fonksiyonudur. Burada Denklem (1) ile Denklem (2)'nin arasında bir ödünüm olacağı beklenmektedir. Denklem (3), her bir fabrikada kullanılan makine merkezinde, $t$ döneminde yapılan işlem saati, makine merkezinin bir dönemdeki üretim kapasitesini geçmemesini sağlayan ve aynı zamanda, fabrikada g makine merkezinin kurulmaması durumunda ise üretim yapılmamasını sağlayan kısıt kümesini ifade eder. Denklem (4), bir fabrikada ya yeni, ya da eski tip makine merkezinin, veya başka bir ifadeyle, tek bir makine merkezi tipinin kurulmasını sağlayan kısıtlar kümesidir. Denklem (5), her fabrikanın akış denge kısıt kümesini içeren denklemdir. Denklem (6), her müşterinin her dönemdeki taleplerinin karşılanmasını sağlayan kısıt kümesidir. Denklem (7), müşterilere gelen ürün miktarıyla toplama merkezleri tarafından toplanan ürün miktarı arasındaki dengeyi kuran denklem setidir. Denklem (8), her bir toplama merkezi için gelen ve giden ürün akışının dengesini kuran kısıt kümesidir. Denklem (9), açılmamış fabrikalara geri kazanılmış ürünlerin gönderilmesini engelleyen denklem kümesidir. Denklem (10)-(11) ise işaret kısıtlarını ifade etmektedir. 


\section{METODOLOJİ: BULANIK AĞIRLIKLANDIRMA YÖNTEMİ (METHODOLOGY: FUZZY WEIGHTED ADDITIVE APPROACH)}

Tiwari ve diğ. (1987) tarafından geliştirilen bulanık ağırlıklandırma yaklaşımı, çok amaçlı optimizasyon fonksiyonuna sahip modelleri çözmek için geliştirilmiş bir yöntemdir. Bu metod, çok amaçlı amaç fonksiyonunu, her bir fonksiyon için hesaplanan bir üyelik fonksiyonu kullanarak, tek amaca indirger. Ağırlıklar $\left(\rho_{1}, \rho_{2}\right)$ karar verici tarafından üç amaç fonksiyonunun ağırlığını yansıtacak şekilde atanır. Bir maksimizasyon problemi için temel ağırlıklı modeli şu şekilde kurulur:

$\operatorname{Maks} V(\mu)=\sum_{\mathrm{i}=1}^{\mathrm{m}} \rho_{\mathrm{i}} \mu_{\mathrm{i}}$

\section{Kisitlar:}

$\mu_{\mathrm{i}}=\frac{\mathrm{G}_{\mathrm{i}}(\mathrm{X})-\mathrm{L}_{\mathrm{i}}}{\mathrm{g}_{\mathrm{i}}-\mathrm{L}_{\mathrm{i}}}$

$\mathrm{AX} \leq \mathrm{b}$

$\mu_{\mathrm{i}} \leq 1$

$\mathrm{X}, \mu_{\mathrm{i}} \geq 0, \quad \mathrm{i}=1,2, \ldots, \mathrm{m}$

$\mathrm{X} \mathrm{x}_{1}, \mathrm{x}_{2}, \ldots, \mathrm{x}_{\mathrm{n}}{ }^{\prime}$ lerden oluşan bir $\mathrm{n}$ boyutlu vektör ve $\mathrm{AX} \leq \mathrm{b}$ ise vektör formatında modelin kısıtlarıdır. Zimmermann (1978)'a göre doğrusal üyelik fonksiyonu, $\mu_{\mathrm{i}}$ i. bulanık amaç için, $\mathrm{G}_{\mathrm{i}}(\mathrm{X}) \geq \mathrm{g}_{\mathrm{i}}$, şu şekilde tanımlanabilir:

$\mu_{i}=\left\{\begin{array}{cc}1 & \text { eğer } G_{i}(X) \geq g_{i} \\ \frac{G_{i}(X)-L_{i}}{g_{i}-L_{i}} & \text { eğer } L_{i} \leq G_{i}(X) \leq g_{i} \\ 0 & \text { eğer } G_{i}(X) \leq L_{i}\end{array}\right\}$

Burada $L_{i}$, bulanık amaç $G_{i}(X)$ için alt sınırdır. Amacın $G_{i}(X) \leq g_{i}$ şeklinde olması durumunda ise üyelik fonksiyonu aşağıdaki gibi tanımlanabilir:

$\mu_{i}=\left\{\begin{array}{cc}1 & \text { eğer } G_{i}(X) \leq g_{i} \\ \frac{U_{i}-G_{i}(X)}{U_{i}-g_{i}} & \text { eğer } g_{i} \leq G_{i}(X) \leq U_{i} \\ 0 & \text { eğer } G_{i}(X) \geq U_{i}\end{array}\right\}$

Burada $U_{i}$ ise, üst tolerans limitidir. Amaç fonksiyonunda ise $V(\mu)$ terimi, bulanık edinim fonksiyonudur. $\mathrm{Bu}$, temel optimizasyon teknikleriyle çözülebilen tek amaçlı bir optimizasyon problemidir.

\section{ÖRNEK VAKA ANALİZİ (CASE STUDY)}

Bu bölümde, geliştirilen matematiksel model ve çözüm yöntemi sayısal bir örnek ile denenmiştir. Geliştirilen tedarik ağında, açılacak fabrikalar ve toplama merkezleri, ayrıca fabrikalarda kullanılacak makine merkezleri de belirlenecek ve gerekli dağıtım planı ortaya çıkarılacaktır. 
Açılabilecek 10 farklı fabrika lokasyonunun, 2 farklı parametrelere sahip yeni/eski makine tipinin, 3 toplama merkezinin belirlendiği, 50 farklı müşteriye 10 zaman periyodu için ürün gönderilmesi gereken bir problemde, tedarik zincirindeki toplam maliyet $\left(\mathrm{Z}_{1}\right)$, ve tedarik zincirindeki toplam karbon salınım miktarı $\left(\mathrm{Z}_{2}\right)$ aynı anda minimize edilmek istenmiştir, bu amaçlara ait ağırlıklar ise ağırlık vektörü $[0.750 .25]^{\mathrm{T}}$ olarak belirlenmiştir. Bu ağırlıklar, bulanık doğrusal programlamanın her bir üyelik fonksiyonu ile çarpılır. Bir sonraki adım, üyelik fonksiyonlarını, yani $\mu_{\mathrm{i}}$ değişkenlerini hesaplamaktır. Üyelik fonksiyonlarını hesaplamak için ilk adım, bir seferde tek bir hedefi optimize edecek şekilde modeli, her bir amaç fonksiyonu adedince çalıştırmaktır.

İlk hedefin üst ve alt sınır optimal değerleri, hedef alınan amaç fonksiyonunun sırasıyla maksimizasyonu ve minimizasyonu şeklinde elde edilir. Süreç kalan diğer hedef için bir kez daha tekrarlanır. Her bir hedef için alt sınır ve üst sınır aynı kısıtlar kümesi kullanılarak hesaplanır. Bulanık formülasyon Tiwari ve diğ. (1987) tarafından geliştirilen tarafından önerilen ağırlıklı edinim modeli kullanılarak yapılır. Çizelge 2, her bir amaç için bulunan üst ve alt sınırları içermektedir.

\begin{tabular}{|c|c|c|}
\hline \multicolumn{3}{|c|}{$\begin{array}{l}\text { Çizelge 2. Üst ve alt sinurlar } \\
\text { Table 2. Upper and lower bounds }\end{array}$} \\
\hline Amaç Fonk. & Maks & Min \\
\hline$Z_{1}$ & 42109709 & 4835858 \\
\hline$Z_{2}$ & 240000 & 10230 \\
\hline
\end{tabular}

Üyelik işlevlerinin doğrusal olduğunu varsayarak, üyelik fonksiyonları Denklem (18) kullanılarak şu şekilde hesaplanır:

$\mu_{1}=\left\{\begin{array}{cc}1 & \text { eğer } Z_{1} \leq 4835858 \\ \frac{42109709-Z_{1}}{42109709-4835858} & \text { eğer } 4835858 \leq Z_{1} \leq 42109709 \\ 0 & \text { eğer } Z_{1} \geq 42109709\end{array}\right\}$

$\mu_{2}=\left\{\begin{array}{cc}1 & \text { eğer } Z_{2} \leq 10230 \\ \frac{240000-Z_{2}}{240000-10230} & \text { eğer } 10230 \leq Z_{2} \leq 240000 \\ 0 & \text { eğer } Z_{2} \geq 240000\end{array}\right\}$

Bu üyelik fonksiyonlarını kullanarak, farklı makine seçenekli kapalı döngü tedarik zinciri için yeni matematiksel formülasyon aşağıdaki gibidir:

Maks $Z=0.75 * \mu_{1}+0.25 * \mu_{2}$

\section{Kisitlar:}

$\mu_{1} \leq \frac{42109709-\mathrm{Z}_{1}}{42109709-4835858}$

$\mu_{2} \leq \frac{240000-\mathrm{Z}_{2}}{240000-10230}$ 
ve kısitlar (3-11) dahil edilerek model tamamlanır.

Yukarıda detaylandırılan matematiksel model, C\# dilinde Visual Studio ortamında ILOG'in CPLEX Concert Technology kullanılarak gerçekleştirilmiştir. Bulanık matematiksel modelin optimal çözümü aşağıdaki Çizelge 3'te verilmiştir.

Çizelge 3. Optimal çözüm

Table 3. Optimal solution

\begin{tabular}{cc}
\hline Amaç Fonk. ve değişkenler & Aldıkları değer \\
\hline $\boldsymbol{Z}_{\mathbf{1}}[\mathbf{4 8 3 5 8 5 8 , 4 2 1 0 9 7 0 9 ]}$ & 4996006 Türk Lirası \\
\hline $\boldsymbol{Z}_{\mathbf{2}}[\mathbf{1 0 2 3 0 , 2 4 0 0 0 0}]$ & 10230 birim ürün \\
\hline$\mu_{\mathbf{1}}$ & 0,996 \\
\hline$\mu_{\mathbf{2}}$ & 1
\end{tabular}

Bu metotla birlikte, $\mathrm{Z}_{1}$, minimum değerine yakın bir değer alırken $\mathrm{Z}_{2}$ minimum değerini alabilmiştir. Şirket, planlama ufku boyunda gerçekleşecek talepler için 8 . ve 10. fabrikalarda yeni tip makine kullanarak üretimi gerçekleştirmiştir.

Modelin ve çözüm yönteminin farklı parametre boyutlarında da denemek faydalı olacaktır (Çizelge 4). Bu sebeple, aşağıdaki parametrelerin kombinasyonları için model optimize edilmiş ve bulunan sonuçlar Çizelge $5^{\prime}$ de verilmiştir.

Çizelge 4. Örnek problem seti için parametreler ve değerleri Table 4. Parameters and their values for the sample problems

\begin{tabular}{ll}
\hline Parametre & Aldıkları Değer \\
\hline Makine tipi & Eski, orta yaşta, yeni makine merkezi (3) \\
\hline Fabrika & 10 \\
\hline Müşteri & $50 ; 100 ; 200$ \\
\hline Zaman periyodu & $10 ; 20$ \\
\hline
\end{tabular}

Buradaki problemlerin çözümünde amaç fonksiyonları için üyelik fonksiyonları hesaplanırken gerekli olan alt sınır-üst sınır değerleri, Çizelge 5'deki min $Z_{1}$ ve $\min Z_{2}$ sütunlarındaki değerler olarak da alınabilir. Modelin ayrıca farklı müşteri talep senaryolarında da verdiği sonuçlar irdelenmiştir. Temel modelde 10 fabrika lokasyonu, 3 farklı makine, 50 müşteri bulunmaktadır (Çizelge 6). 
Çizelge 5. Problem örnekleri için bulunan optimal çözümler Table 5. Optimal solutions for the problem sets

\begin{tabular}{|c|c|c|c|c|}
\hline & $\operatorname{Min} Z_{1}$ & $\operatorname{Min} Z_{2}$ & Bulanık Çözüm Y. & Optimal Z Değerleri \\
\hline $\begin{array}{l}\text { Fabrika }=10 \\
\text { Müşteri }=50 \\
\text { Zaman periyodu=10 }\end{array}$ & $\begin{array}{c}Z_{1}=2134041 \\
Z_{2}=6820\end{array}$ & $\begin{array}{c}Z_{1}=9543368 \\
Z_{2}=1705\end{array}$ & $\begin{array}{c}\mu_{1}=0,853 \\
\mu_{2}=1\end{array}$ & $\begin{array}{c}Z_{1}=3223212 \\
Z_{2}=1705\end{array}$ \\
\hline $\begin{array}{l}\text { Fabrika }=10 \\
\text { Müşteri }=50 \\
\text { Zaman periyodu=20 }\end{array}$ & $\begin{array}{c}Z_{1}=3665436 \\
Z_{2}=13165\end{array}$ & $\begin{array}{c}Z_{1}=10971830 \\
Z_{2}=3291\end{array}$ & $\begin{array}{c}\mu_{1}=0,878 \\
\mu_{2}=1\end{array}$ & $\begin{array}{c}Z_{1}=4556816 \\
Z_{2}=3291\end{array}$ \\
\hline $\begin{array}{l}\text { Fabrika }=10 \\
\text { Müşteri=100 } \\
\text { Zaman periyodu=10 }\end{array}$ & $\begin{array}{c}Z_{1}=3820273 \\
Z_{2}=8266\end{array}$ & $\begin{array}{c}Z_{1}=10791940 \\
Z_{2}=3444\end{array}$ & $\begin{array}{c}\mu_{1}=0,912 \\
\mu_{2}=1\end{array}$ & $\begin{array}{c}Z_{1}=4433780 \\
Z_{2}=3444\end{array}$ \\
\hline $\begin{array}{l}\text { Fabrika }=10 \\
\text { Müşteri=200 } \\
\text { Zaman periyodu=10 }\end{array}$ & $\begin{array}{c}Z_{1}=6555044 \\
Z_{2}=15845\end{array}$ & $\begin{array}{c}Z_{1}=13445570 \\
Z_{2}=6602\end{array}$ & $\begin{array}{c}\mu_{1}=0,933 \\
\mu_{2}=1\end{array}$ & $\begin{array}{c}Z_{1}=7016709 \\
Z_{2}=6602\end{array}$ \\
\hline $\begin{array}{l}\text { Fabrika }=10 \\
\text { Müşteri=100 } \\
\text { Zaman periyodu=20 }\end{array}$ & $\begin{array}{c}Z_{1}=7066142 \\
Z_{2}=17283\end{array}$ & $\begin{array}{c}Z_{1}=16149890 \\
Z_{2}=6911\end{array}$ & $\begin{array}{c}\mu_{1}=0,956 \\
\mu_{2}=1\end{array}$ & $\begin{array}{c}Z_{1}=7465827 \\
Z_{2}=6911\end{array}$ \\
\hline $\begin{array}{l}\text { Fabrika }=10 \\
\text { Müşteri }=200 \\
\text { Zaman periyodu=20 }\end{array}$ & $\begin{array}{c}Z_{1}=12875410 \\
Z_{2}=13395\end{array}$ & $\begin{array}{c}Z_{1}=19159260 \\
Z_{2}=13395\end{array}$ & $\begin{array}{c}\mu_{1}=0,983 \\
\mu_{2}=1\end{array}$ & $\begin{array}{c}Z_{1}=12982235 \\
Z_{2}=13395\end{array}$ \\
\hline
\end{tabular}

Çizelge 6. Problem örnekleri için bulunan optimal çözümler Table 6. Optimal solutions for the problem sets

\begin{tabular}{ccccc}
\hline Talep Fonk. & Min $Z_{\mathbf{1}}$ & Min $Z_{\mathbf{2}}$ & Bulanık Çözüm & Optimal Z Değerleri \\
\hline \multirow{2}{*}{ uniform(20,50) } & $Z_{1}=1334750$ & $Z_{1}=8835640$ & $\mu_{1}=0,835$ & $Z_{1}=2572397$ \\
& $Z_{2}=3420$ & $Z_{2}=855$ & $\mu_{2}=0,974$ & $Z_{2}=921$ \\
\hline \multirow{2}{*}{ uniform(50,100) } & $Z_{1}=2406920$ & $Z_{1}=9441475$ & $\mu_{1}=0,896$ & $Z_{1}=3138514$ \\
& $Z_{2}=4401$ & $Z_{2}=1833$ & $\mu_{2}=1$ & $Z_{2}=1833$ \\
\hline \multirow{2}{*}{ uniform(100,200) } & $Z_{1}=4298965$ & $Z_{1}=10611630$ & $\mu_{1}=0,896$ & $Z_{1}=4955482$ \\
& $Z_{2}=9489$ & $Z_{2}=3796$ & $\mu_{2}=1$ & $Z_{2}=3796$ \\
\hline \multirow{2}{*}{ uniform(150,300) } & $Z_{1}=6208893$ & $Z_{1}=13053850$ & $\mu_{1}=0,826$ & $Z_{1}=7399916$ \\
& $Z_{2}=15506$ & $Z_{2}=5476$ & $\mu_{2}=1$ & $Z_{2}=5476$ \\
\hline \multirow{2}{*}{ uniform(200,400) } & $Z_{1}=8626236$ & $Z_{1}=16818930$ & $\mu_{1}=0,923$ & $Z_{1}=9257073$ \\
& $Z_{2}=11512$ & $Z_{2}=7299$ & $\mu_{2}=0,937$ & $Z_{2}=7564$ \\
\hline \multirow{2}{*}{ uniform(250,500) } & $Z_{1}=10899530$ & $Z_{1}=20551950$ & $\mu_{1}=0,917$ & $Z_{1}=11700681$ \\
& $Z_{2}=15261$ & $Z_{2}=9119$ & $\mu_{2}=1$ & $Z_{2}=9119$ \\
\hline \multirow{2}{*}{ uniform(500,1000) } & $Z_{1}=20336270$ & $Z_{1}=30179610$ & $\mu_{1}=0,792$ & $Z_{1}=22383685$ \\
& $Z_{2}=36909$ & $Z_{2}=18227$ & $\mu_{2}=0,984$ & $Z_{2}=18525$ \\
\hline \multirow{2}{*}{ uniform(750,1500) } & $Z_{1}=31056470$ & $Z_{1}=37345960$ & $\mu_{1}=0,808$ & $Z_{1}=32264052$ \\
& $Z_{2}=33689$ & $Z_{2}=27334$ & $\mu_{2}=1$ & $Z_{2}=27334$ \\
\hline
\end{tabular}

Çizelge 5 ve 6'dan da görüleceği üzere bulanık çözüm sonuçları, üretimden kaynaklı toplam karbon miktarının minimizasyonunu bir örnek dışında optimal bir şekilde gerçekleştirmiştir. Küçük boyutlu problemlerde toplam maliyetin minimizasyonu, büyük boyutlu problemlere göre daha düşük çıktı̆̆1 görülmektedir. Bunun sebebi ise, problem boyutu büyüdükçe talebin karşılanabilmesi için kurulan fabrika sayısının artması ve üretimin de yeni tip makine alanlarında gerçekleştirilmek zorunda olmasıdır, yani makineler arasında seçim yaparak hedefler arasında ödünleşme imkanı da azalmaktadır. 


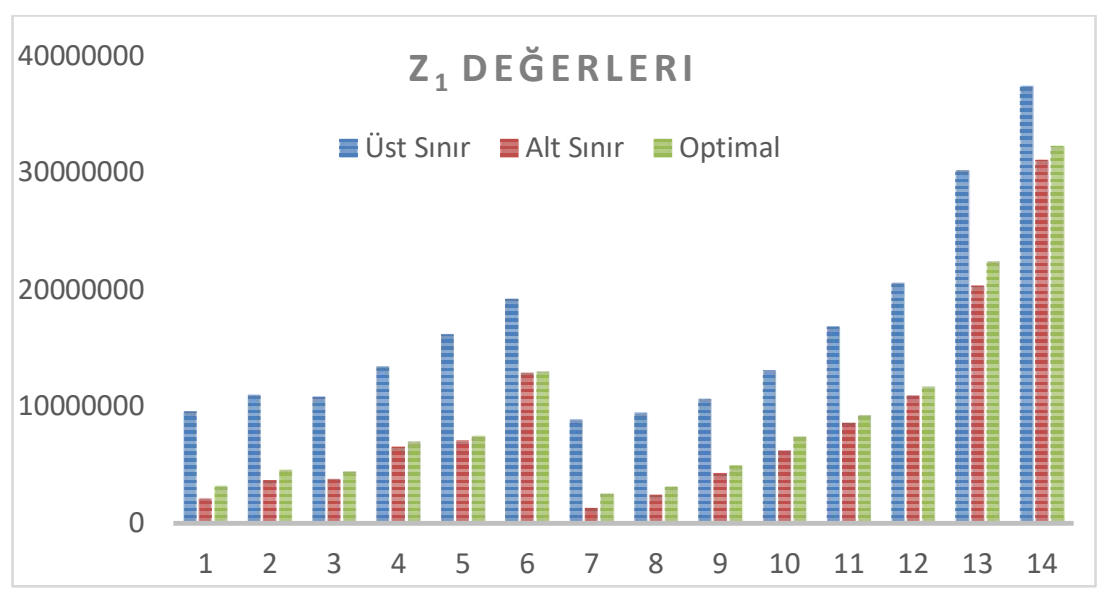

Şekil 2. Z1 için Üst Sınır, Alt sınır Değerleri ve Optimal sonuçlar

Figure 2. Upper, Lower bounds and Optimal values for Z1

Şekil 2 ve Şekil 3'den de görüleceği üzere 2 amaç fonksiyonunun optimal değerleri, alt sınırlarına oldukça yakın olarak bulunmuştur. Bu da uygulanan bulanık ağırlıklandırma yönteminin başarılı sonuçlar verdiğini göstermektedir.

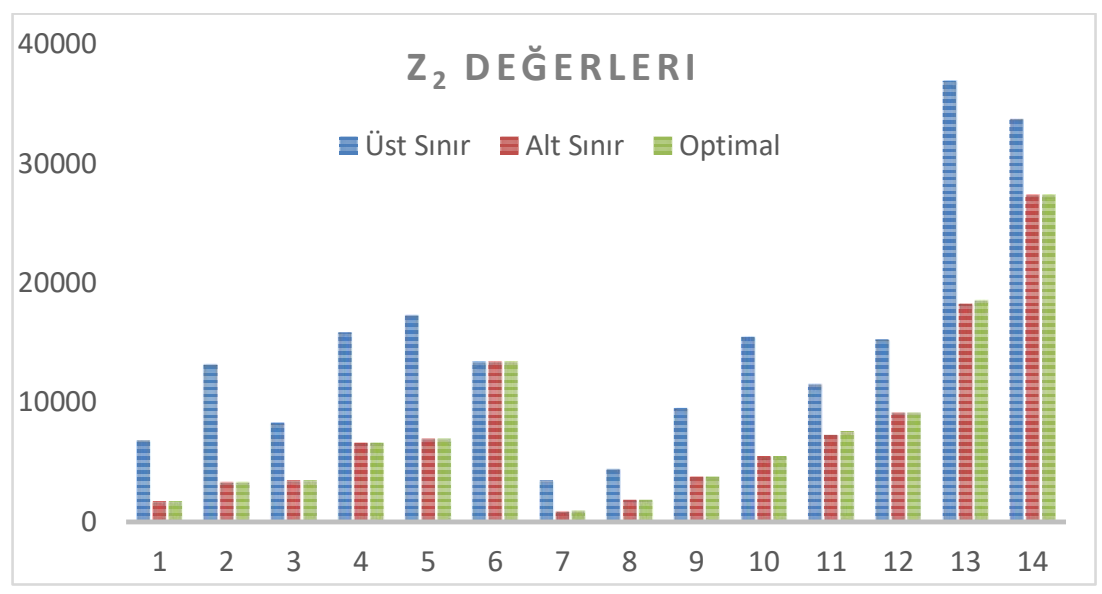

Şekil 3. Z2 için Üst Sınır, Alt sınır Değerleri ve Optimal sonuçlar

Figure 3. Upper, Lower bounds and Optimal values for Z2

Ayrıca model, üretimde planlama ufku uzadıkça veya toplam talebin arttığı senaryolarda yeni nesil makinelerde üretimin yapılmasına karar vermiştir, çünkü baştaki yüksek satın alma maliyetinin kompanse edilmesi kolaylaşmakta ve böylece de daha az karbon salınımına sebebiyet verilmektedir. 


\section{SONUÇ (CONCLUSION)}

Pratik açıdan bakıldığında işletmelerin tek bir tedarik zinciri hedefi altında çalıştığını söyleyemeyiz, daha çok farklı ve birbirleriyle çelişen ekonomik, çevresel, organizasyonel ve operasyonel hedeflere aynı anda ulaşmak istemektedirler. Çok amaçlı problemlerin çıkış noktası da birden çok amacın aynı anda optimize edilmesi gereksinimidir.

Bu çalışmada, çok dönemli kapalı döngü tedarik zinciri ağ tasarım probleminin optimizasyonu için bir çok amaçlı karmaşık tamsayılı doğrusal programlama modeli formüle edilmiştir. Model, farklı makine tiplerinde faaliyet gösteren tesislerin toplam operasyon maliyeti ve toplam karbon emisyonları olmak üzere iki ayrı amacın minimizasyonunu hedeflerken, üretim ve dağıtım stratejilerini belirlemekte ve kullanılacak makine tiplerine de karar vermektedir. Bu iki amaçlı kapalı döngü tedarik zinciri modelinin çözümü için Tiwari ve diğ. (1987) tarafından geliştirilen bulanık ağırlıklandırma yaklaşımı kullanılmıştır. Sonuçlar, üretimde planlama ufku uzadıkça ve/veya toplam talebin arttığı senaryolarda, yüksek verimli, düşük enerji harcayan yeni nesil makine alımına yönlenilmesi gerektiğini ortaya koymaktadır, çünkü planlama ufku uzadıkça veya toplam talebin daha yüksek olduğu senaryolarda ile baştaki yüksek satın alma maliyeti rahatlıkla kompanse edilebilmekte, başabaş noktasına daha çabuk ulaşılabilmekte ve böylece de daha az karbon salınımına sebebiyet verilmektedir.

Gelecekte, çok amaçlı tedarik zinciri problemleri için farklı çözüm yöntemleri geliştirilebilir ve sonuçlar birbirleriyle karşılaştırılabilir. Makinelerin yıllanmasına bağlı olarak parametre değerlerinin, örneğin işletim maliyeti, emisyon oranları, ürün kalitesinin değişkenlik göstermesi, verimliliğin zamanla periyodu boyunca düşmesi, ürünlerin geri kazanım oranının makinelerin yeni/eski olmasına bağlı olarak değişmesi gibi seçenekler düşünülebilir.

\section{KAYNAKLAR (REREFENCES)}

Altiparmak, F., Gen, M., Lin, L., Paksoy, T., 2006, "A genetic algorithm approach for multi-objective optimization of supply chain networks", Computers \& Industrial Engineering, 51(1), 196-215. doi:https://doi.org/10.1016/j.cie.2006.07.011

Amid, A., Ghodsypour, S. H., O'Brien, C., 2009, "A weighted additive fuzzy multiobjective model for the supplier selection problem under price breaks in a supply Chain", International Journal of Production Economics, 121(2), 323-332. doi:http://dx.doi.org/10.1016/j.ijpe.2007.02.040

Arikan, F., 2013, "A fuzzy solution approach for multi objective supplier selection", Expert Systems with Applications, 40(3), 947-952. doi:10.1016/j.eswa.2012.05.051

Banasik, A., Kanellopoulos, A., Claassen, G. D. H., Bloemhof-Ruwaard, J. M., van der Vorst, J. G. A. J., 2017, "Closing loops in agricultural supply chains using multi-objective optimization: A case study of an industrial mushroom supply chain", International Journal of Production Economics, 183, 409-420. doi:https://doi.org/10.1016/j.ijpe.2016.08.012

Chan, F. T. S., Jha, A., Tiwari, M. K., 2016, "Bi-objective optimization of three echelon supply chain involving truck selection and loading using NSGA-II with heuristics algorithm", Applied Soft Computing, 38, 978-987. doi:10.1016/j.asoc.2015.10.067

de Groot, H. L. F., Verhoef, E. T., Nijkamp, P., 2001, "Energy saving by firms: decision-making, barriers and policies", Energy Economics, 23(6), 717-740. doi:https://doi.org/10.1016/S0140-9883(01)000834

Fahimnia, B., Sarkis, J., Eshragh, A., 2015, "A tradeoff model for green supply chain planning:A leannessversus-greenness analysis", Omega, 54, 173-190. doi:10.1016/j.omega.2015.01.014

Fernando, Y., Wah, W. X., 2017, "The impact of eco-innovation drivers on environmental performance: Empirical results from the green technology sector in Malaysia", Sustainable Production and Consumption, 12, 27-43. doi:https://doi.org/10.1016/j.spc.2017.05.002

Iida, T., 2012, "Coordination of cooperative cost-reduction efforts in a supply chain partnership", $\begin{array}{llll}\text { European Journal of Operational Research, 222(2), 180-190. } & \text {. }\end{array}$ doi:https://doi.org/10.1016/j.ejor.2012.03.029 
Jaffe, A. B., Newell, R. G., Stavins, R. N., 2005, "A tale of two market failures: Technology and environmental policy", Ecological Economics, 54(2), 164-174. doi:https://doi.org/10.1016/j.ecolecon.2004.12.027

Kavitha, C. a. V., C., 2013, "Multi Objective Fuzzy Linear Programming Technique for Weighted Additive Model for Supplier Selection in Supply Chain Management", International Journal of Applied Mathematics and Informatics.

Mehlawat, M. K., Kumar, S., 2017, "A multiobjective optimization model for optimal supplier selection in multiple sourcing environment", 26, 18.

Pan, W., Wang, F., Guo, Y., Liu, S., 2015, "A Fuzzy Multiobjective Model for Supplier Selection under Considering Stochastic Demand in a Supply Chain", Mathematical Problems in Engineering, 2015, 8. doi:10.1155/2015/174585

Sadeghi Rad, R., Nahavandi, N., 2018, "A novel multi-objective optimization model for integrated problem of green closed loop supply chain network design and quantity discount", Journal of Cleaner Production, 196, 1549-1565. doi:https://doi.org/10.1016/j.jclepro.2018.06.034

Seifbarghy, M., Pourebrahim Gilkalayeh, A., Alidoost, M., 2011, "A Comprehensive Fuzzy Multiobjective Supplier Selection Model under Price Brakes and Using Interval Comparison Matrices", Journal of Industrial and Systems Engineering, 4(4), 224-244.

Shaw, K., Shankar, R., Yadav, S. S., Thakur, L. S., 2012, "Supplier selection using fuzzy AHP and fuzzy multi-objective linear programming for developing low carbon supply chain", Expert systems with applications, 39(9), 8182-8192.

Soleimani, H., Govindan, K., Saghafi, H., Jafari, H., 2017, "Fuzzy multi-objective sustainable and green closed-loop supply chain network design", Computers \& Industrial Engineering, 109, 191-203. doi:https://doi.org/10.1016/j.cie.2017.04.038

Talaei, M., Farhang Moghaddam, B., Pishvaee, M. S., Bozorgi-Amiri, A., Gholamnejad, S., 2016, "A robust fuzzy optimization model for carbon-efficient closed-loop supply chain network design problem: a numerical illustration in electronics industry", Journal of Cleaner Production, 113, 662673. doi:10.1016/j.jclepro.2015.10.074

Teng, M.-J., Wu, S.-Y., Chou, S. J.-H., 2014, "Environmental Commitment and Economic Performance Short-Term Pain for Long-Term Gain", Environmental Policy and Governance, 24(1), 16-27. doi:doi:10.1002/eet.1634

Tiwari, R. N., Dharmar, S., Rao, J. R., 1987, " Fuzzy goal programming - An additive model", Fuzzy Sets and Systems, 24(1), 27-34. doi:https://doi.org/10.1016/0165-0114(87)90111-4

Wang, F., Lai, X., Shi, N., 2011, "A multi-objective optimization for green supply chain network design", Decision Support Systems, 51(2), 262-269. doi:https://doi.org/10.1016/j.dss.2010.11.020

Zimmermann, H.-J., 1978, "Fuzzy programming and linear programming with several objective functions", Fuzzy Sets and Systems, 1(1), 45-55. 